\title{
ATTACKING AN EPIDEMIC
}

Despite a huge amount of funding and research, regional and individual differences in cancer trends make it a hard disease to wipe out. By Mike May.

\section{A GLOBAL KILLER}

The number of people who die from cancer varies greatly around the world, often because of differences in behaviour and healthcare.

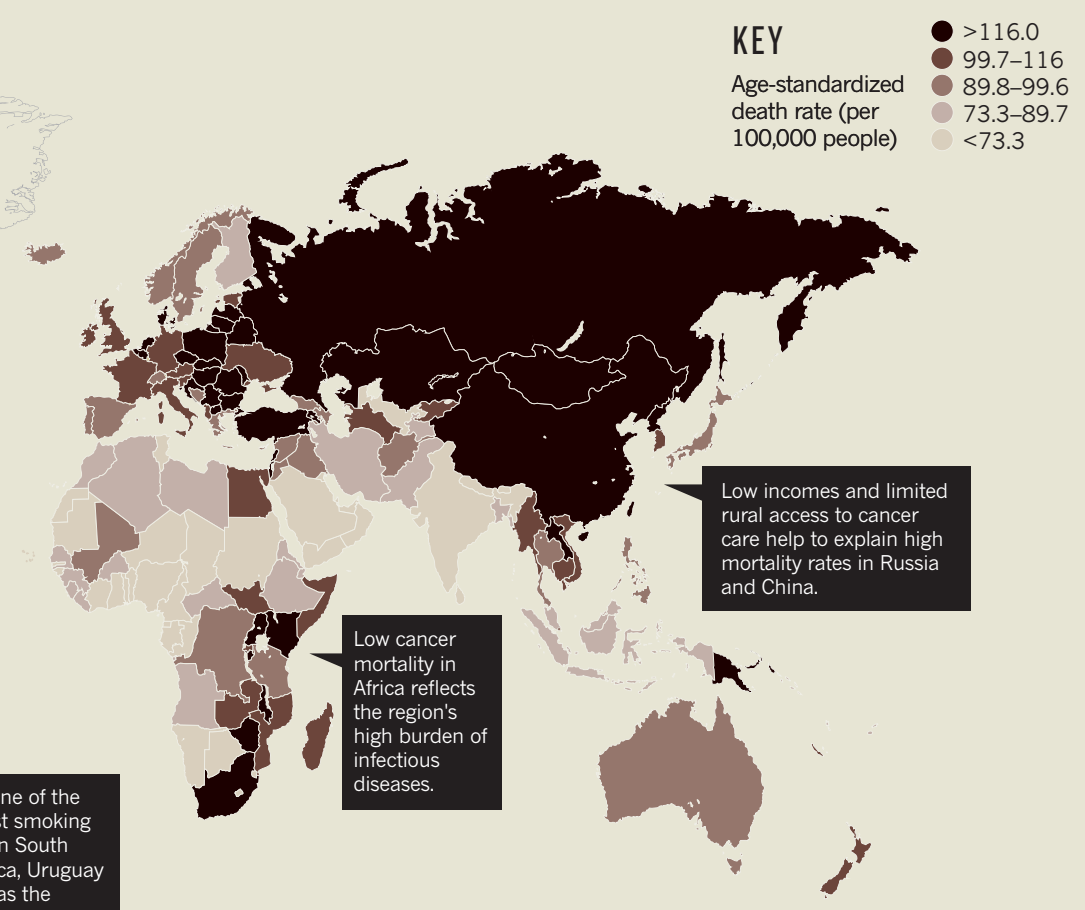

\section{AGE-OLD PROBLEM}

A dramatic change happens around the age of 20 , when the main cancers being diagnosed in the United States start to shift from mainly leukaemia to predominantly digestive, prostate, lung and breast.

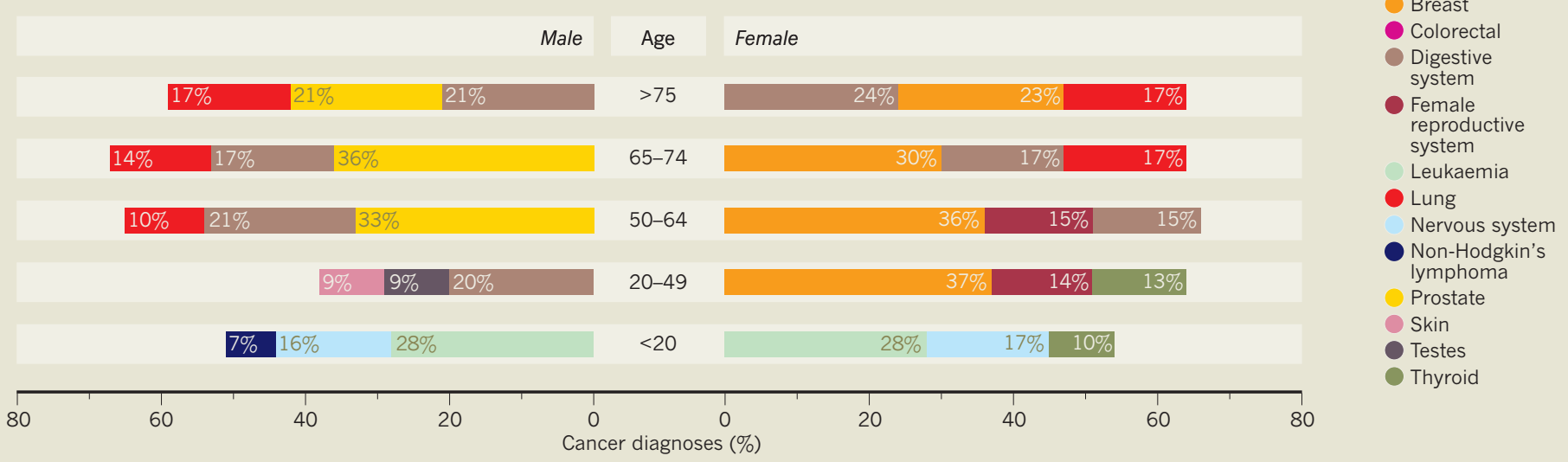

\section{MONEY MATTERS}

In 2013 , the US National Institutes of Health spent US $\$ 2.6$ billion on cancer research, and more than one-quarter of that went to breast cancer.

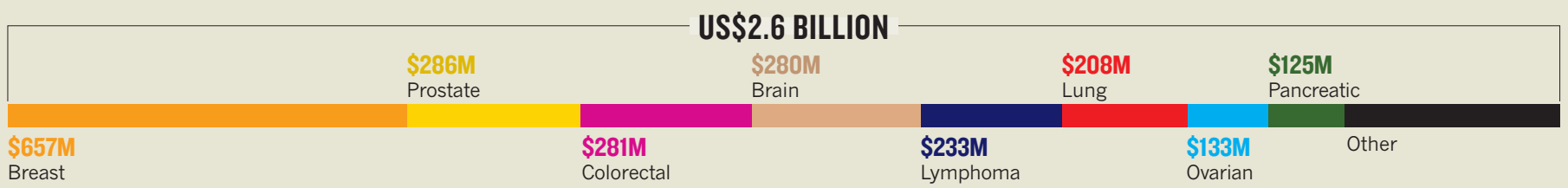




\section{POINTS OF ATTACK}

With the exception of sub-Saharan Africa, lung cancer is one of the top three cancer killers in all regions. Breast, colorectal and prostate also feature prominently.

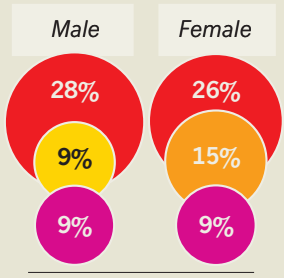

North America

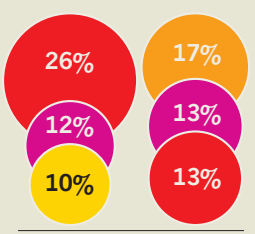

Europe

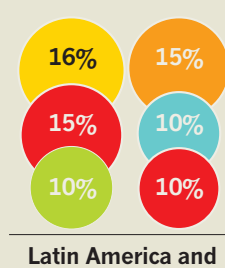

the Caribbean

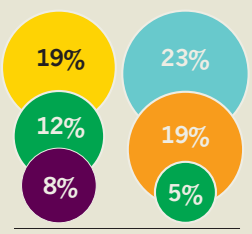

Sub-Saharan Africa

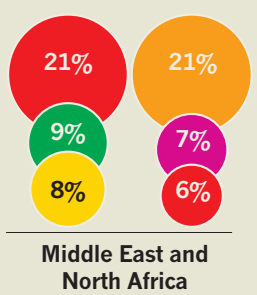

KEY

Breast

Cervical

Colorectal

Kaposi's

sarcoma

Liver

Lung

Prostate

Stomach

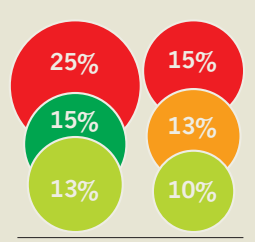

Asia

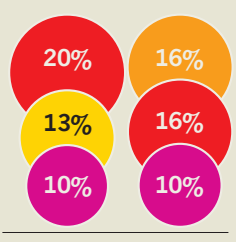

Oceania

\section{DEADLY DISCREPANCY}

Gaps between diagnoses and mortality are most prominent for breast and prostate cancer.

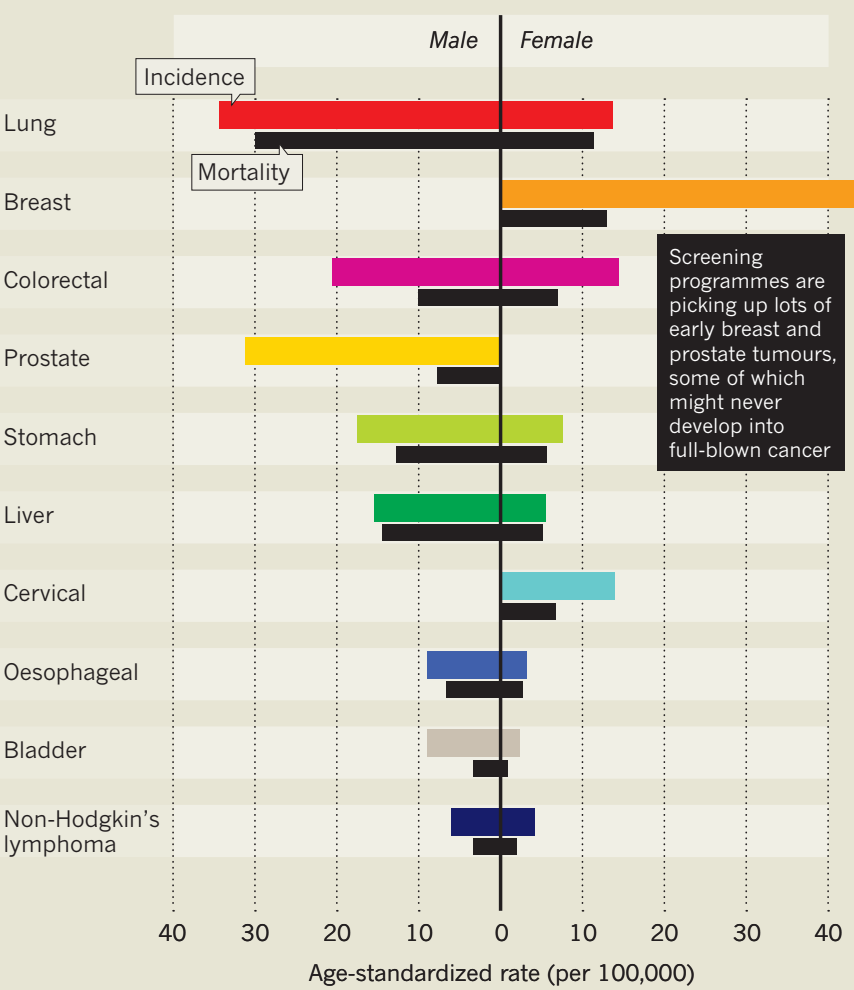

\section{RATE CHANGES}

Among other factors, public-health measures have influenced the number of US people being diagnosed with certain cancers.



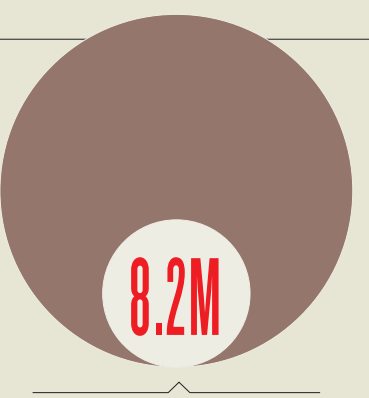

In 2012, cancer contributed to $15 \%$ of al deaths worldwide, with 8.2 million in total.

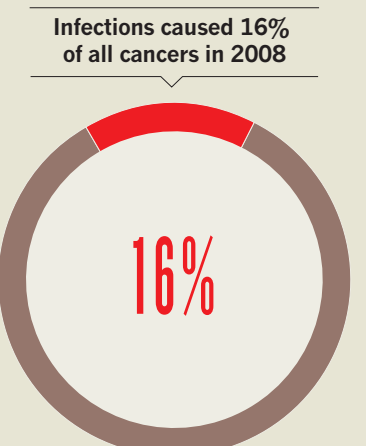

\section{HIGHS AND LOWS}

Some cancers have much better prognoses than others. Breast and prostate cancer have benefited from improved treatments and early detection.

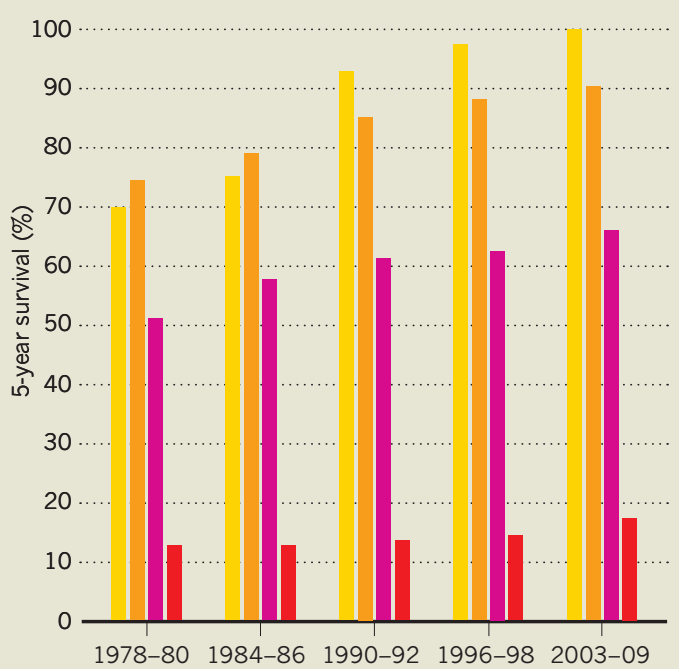

